\title{
ANALISANDO A IMPLEMENTAÇÃO DE UMA ABORDAGEM CTS NA SALA DE AULA DE QUÍMICA
}

\author{
Analysing a teaching sequence with STS approach \\ applied in the Chemistry classroom
}

\author{
Ruth do Nascimento Firme ${ }^{1}$ \\ Edenia Maria Ribeiro do Amaral ${ }^{2}$
}

\begin{abstract}
Resumo: Neste artigo, analisamos como dois professores de química desenvolveram, em sala de aula, uma intervenção didática previamente planejada com enfoque CTS, buscando identificar obstáculos e dificuldades para o estabelecimento de uma prática docente pautada nessa perspectiva de ensino. As aulas foram filmadas, transcritas e os dados analisados a partir da dinâmica discursiva estabelecida entre professores e alunos. A análise apontou que dificuldades no desenvolvimento das atividades podem estar associadas não somente à prática docente, mas também a fatores tais como: ausência de informações técnicas e científicas sobre o tema; velocidade da inovação tecnológica; complexidade cientifica na abordagem de alguns temas; dificuldade em articular adequadamente conceitos científicos com questões tecnológicas, associadas a um tema social relevante; e dificuldade de material didático que suporte as discussões de temas específicos na sala de aula.
\end{abstract}

Palavras-chave: Ensino de Química. Implementação de abordagem CTS.

\begin{abstract}
In this work, we have analyzed how two Chemistry's teachers developed a planned teaching sequence starting from a STS perspective in their classrooms, trying to identify obstacles and difficulties in engaging this pedagogical practice and taking into account this perspective for science teaching. Lessons were video recorded, transcribed and data were analyzed considering the discursive dynamic established between the teacher and the students. Data analysis showed that possible obstacles to developing didactic activities cannot be associated only with the teacher's practice and experience, but also can be related to aspects, such as: the lack of technical information about the theme studied; continuous improvement related to the technological artifacts; themes requiring a more complex scientific understanding; difficulties in properly putting together scientific concepts and technology implicated with relevant social problems; and difficulty with appropriate didactical sources to approach these specific subjects in science classrooms.
\end{abstract}

Keywords: Chemistry teaching. Application of STS approach.

${ }^{1}$ Graduada em Química, mestre em Ensino das Ciências. Professora de Química, Rede Pública de Ensino, Estado de Pernambuco. Recife, PE, Brasil. <ruthquimica@yahoo.com.br>

${ }^{2}$ Graduada em Química, doutora em Educação. Docente, Departamento de Química/Programa de PósGraduação em Ensino das Ciências, Universidade Federal Rural de Pernambuco. Recife, PE, Brasil.

<edsamaral@uol.com.br>

${ }^{1}$ Rua Professor Francisco Xavier Paes Barreto, 224, apto. 01

Casa Caiada - Olinda, PE

$53.130-240$

383

Ciência : Ẽ Educação, v. 17, n. 2, p. 383-399, 2011 
Firme, R. N.; Amaral, E. M. R.

\section{Introdução}

Neste trabalho, analisamos a aplicação de uma intervenção didática, planejada na perspectiva CTS (Ciência-Tecnologia-Sociedade), em duas turmas de química de duas escolas públicas de Recife. O nosso objetivo foi identificar possíveis obstáculos para a construção de uma prática docente nessa perspectiva de ensino. A análise foi feita considerando-se aspectos da aplicação e adequação do planejamento feito pelos professores e as ações docentes para o desenvolvimento das atividades em sala de aula. Em uma etapa anterior deste trabalho, buscamos discutir, com os professores envolvidos, pressupostos teóricos e metodológicos, concepções e ações requeridas para a implementação da orientação CTS para o ensino em sala de aula. A análise dessa etapa inicial mostrou que algumas concepções docentes e aspectos da prática pedagógica já constituída podem interferir na compreensão dessa proposta de ensino, sendo relevante realizar uma formação prévia para a ação em sala de aula (FIRME; AMARAL, 2008).

Na perspectiva CTS para o Ensino de Ciências, é reconhecida a necessária articulação dos conhecimentos científicos e tecnológicos com o contexto social, tendo como objetivo preparar cidadãos capacitados para julgar e avaliar as possibilidades, limitações e implicações do desenvolvimento científico e tecnológico. Para o Ensino de Química, Santos e Schnetzler (1996) propõem a formação do indivíduo visando o uso racional do conhecimento químico e o desenvolvimento de atitudes e valores de participação social. Dessa forma, consideramos que os alunos precisam se apropriar do conhecimento químico para argumentarem de maneira crítica e reflexiva sobre inter-relações entre o desenvolvimento científico e tecnológico e a organização da sociedade, incluindo o ambiente onde ela se insere. Em outras palavras, o conhecimento sobre princípios científicos e suas aplicações em artefatos tecnológicos poderá contribuir para que o indivíduo participe ativamente de contextos sociais e julgue responsavelmente situações.

$\mathrm{Na}$ pesquisa em Ensino de Ciências, diversos trabalhos apresentam propostas de ensino com uma orientação curricular CTS. Na perspectiva CTS, o objetivo é promover uma formação que possibilite aos indivíduos tomarem decisões responsáveis acerca da qualidade de vida em uma sociedade impregnada de ciência e tecnologia (ACEVEDO DÍAZ, 1996a). Nesse tipo de orientação para o ensino, é proposta a discussão de problemáticas socioambientais e de conceitos da ciência e da tecnologia pertinentes às mesmas, buscando levantar questões sobre as implicações sociais do desenvolvimento científico e tecnológico (MARTINS, 2003). Nessa direção, para o Ensino de Ciências torna-se necessária a discussão sobre as relações mútuas entre a ciência, tecnologia e sociedade, buscando: dar sentido aos conhecimentos escolares, potencializando suas utilidades e funcionalidades em outros âmbitos; colaborar para formar cidadãos capazes de opinar com conhecimento de causa e responsabilidade social sobre os diversos problemas do nosso tempo; contribuir para evitar rupturas entre a ciência e a tecnologia, uma vez que, no mundo atual, são âmbitos bastante difusos; e servir de elemento motivador para os alunos (ACEVEDO ROMERO; ACEVEDO DÍAZ, 2002).

No que se refere aos aspectos pedagógicos para uma abordagem CTS ao ensino, ou seja, para a implementação da orientação CTS na sala de aula, os conteúdos das disciplinas científicas devem incluir temas sociais, sendo esta uma questão central (SANTOS; SCHNETZLER, 1997). Dessa forma, os problemas científicos abordados nas aulas estão associados às necessidades sociais e aos processos tecnológicos. De acordo com Santos e Schnetzler (1997, p. 74), a inclusão dos temas sociais é justificada pelo fato de eles "evidenciarem as inter-relações 
Analisando a implementação de uma abordagem ...

dos aspectos da ciência, tecnologia e sociedade e propiciarem condições para o desenvolvimento de atitudes de tomada de decisão dos alunos". Com relação às questões metodológicas, uma abordagem CTS sugere a utilização de várias estratégias de ensino, tais como: palestras com especialistas, visitação a fábricas, resolução de problemas abertos, sessões de questionamentos, debates, e experimentos em laboratório (SANTOS; SCHNETZLER, 1997). Tais estratégias exigem a associação de campos de conhecimentos tecnológico, social, científico e ético (MACEDO; KATZKOWICK, 2003). A abordagem dos temas sociais na perspectiva de ensino CTS segue uma estrutura característica que, segundo Aikenhead (1990 apud TEIXEIRA, 2003), resulta da adoção de etapas: introdução de uma questão social; análise de uma tecnologia relacionada à questão social; definição de conceitos e habilidades científicas em função da tecnologia e da questão social introduzida; retomada da tecnologia em função dos conceitos e habilidades científicas estudados; e retomada da questão social na busca de possíveis soluções. Teixeira (2003) considera que a estrutura proposta, além de extrapolar a dimensão meramente conceitual, pode contribuir de maneira efetiva para um salto qualitativo na formação do cidadão. Nesse sentido, busca-se potencializar a ação social dos futuros cidadãos, e essa ênfase na responsabilidade social aparece como elemento preciso no currículo para complementar um enfoque mais tradicionalista de educação científica (BUSTAMANTE, 1997).

Outros aspectos que são importantes para uma abordagem CTS na sala de aula dizem respeito às concepções de ciência, tecnologia, sociedade e às suas inter-relações, apresentadas, sobretudo, pelos professores. Segundo alguns autores (CACHAPUZ et al, 2005; MCKAVANAGH; MAHER, 1982 apud SANTOS; SCHENZTZLER, 1997), algumas concepções seriam desejáveis para promover uma experiência didática enraizada no pensamento CTS. Com base nas colocações feitas por estes autores, propomos, a seguir, um quadro que resume algumas dessas concepções.

No Quadro 1, são apontadas significativas inter-relações entre ciência, tecnologia e sociedade, e a compreensão dessas inter-relações parece se constituir como ponto central para termos concretamente uma abordagem CTS no Ensino de Ciências. Com isso, consideramos

Quadro 1. Concepções esperadas sobre Ciência, Tecnologia e Sociedade em uma abordagem CTS.

\begin{tabular}{|l|l|}
\hline \multicolumn{1}{|c|}{ Aspectos da perspectiva CTS } & \multicolumn{1}{c|}{ Concepções esperadas } \\
\hline 1- Natureza da Ciência & $\begin{array}{l}\text { Ciência - compreendida como construção humana e inserida num } \\
\text { contexto sociocultural, que gera conhecimentos condicionados por } \\
\text { interesses diversos. }\end{array}$ \\
\hline 2 - Natureza da Tecnologia & $\begin{array}{l}\text { Tecnologia - compreendida a partir da aplicação de conhecimentos } \\
\text { (científicos ou não) para satisfazer as necessidades humanas, e que } \\
\text { contribui para a construção de novos conhecimentos. }\end{array}$ \\
\hline 3- Natureza da Sociedade & $\begin{array}{l}\text { Sociedade - compreendida como um sistema estruturado de relações } \\
\text { sociais, no qual se compartilha uma cultura científico-tecnológica e que } \\
\text { deve tomar parte na constituição e aplicação do conhecimento científico } \\
\text { e tecnológico. }\end{array}$ \\
\hline 4-As inter-relações & $\begin{array}{l}\text { Ciência e Tecnologia - compreendidas como domínios distintos que se } \\
\text { influenciam mutuamente na construção de conhecimentos, e que tanto } \\
\text { promovem modificações nas formas de vida da sociedade, como podem } \\
\text { ser influenciadas por esta sociedade através de políticas públicas. }\end{array}$ \\
\hline
\end{tabular}


que são colocados desafios para o desenvolvimento de estratégias didáticas e de uma prática docente orientadas nessa perspectiva para o ensino.

Em uma abordagem CTS aplicada ao Ensino de Química, consideramos que não se podem enfatizar apenas dimensões conceituais no processo ensino-aprendizagem. O tratamento de informações e teorias científicas que não tenham relação com o cotidiano do aluno, com o contexto social e tecnológico em que ele vive, inspira, na maioria das vezes, uma aprendizagem mecânica de informações e teorias. Nesse sentido, fazer a opção por uma abordagem CTS representa ampliar a visão para o ensino, superando reducionismos, como, por exemplo, a ênfase unicamente nos conteúdos e a ausência de contextualização, e buscar um ensino que se constitua efetivamente como instrumento para a formação do individuo, que amplie seus horizontes culturais e sua autonomia no exercício da cidadania (BRASIL, 2002). Consideramos que os conhecimentos químicos devem levar o aluno a construir uma visão de mundo mais articulada com o contexto das aplicações do conhecimento científico e tecnológico e suas implicações ambientais, sociais, políticas e econômicas. Nesse contexto, parece-nos que se torna necessária a reorganização dos conteúdos escolares e dos procedimentos metodológicos empregados na abordagem dos conteúdos.

Um ponto importante a considerar é que uma perspectiva CTS de ensino requer modificação no perfil tradicional da ação docente (ACEVEDO DÍAZ, 1996b). A proposta de incorporar, ao ensino, uma discussão sobre as inter-relações CTS dependerá da disponibilidade para a mudança e a renovação, por parte dos professores. Nesse sentido, Bustamante (1997) propõe, aos professores, as seguintes orientações: criar, no aluno, a capacidade de relacionar conceitos de diferentes áreas do conhecimento, estimulando o seu espírito crítico; promover debates sociais acerca da implantação, eliminação ou substituição de uma determinada tecnologia com o objetivo de preparar cidadãos com voz e opiniões fundamentadas; fomentar, nos alunos, atitudes de reconhecimento das possibilidades de melhoria de vida relativas ao desenvolvimento científico e tecnológico; distinguir a dupla função da tecnociência - o seu papel como instrumento e o seu papel como criadora de modelos para entender o ser humano e a sociedade em que vive; atender ao estudo das relações ciência, tecnologia e sociedade considerando as demandas de uma sociedade constituídas com base na informação.

Partindo de diversos estudos com professores que trabalham numa perspectiva CTS, Penick (1993 apud ACEVEDO DÍAZ, 1996a) identificou um conjunto de ações docentes características dessa perspectiva de ensino, dentre as quais podemos pontuar: dedicar tempo para o planejamento das aulas; tornar flexível a ordem curricular dos conteúdos; favorecer um clima agradável na aula para promover a interação; estimular questionamentos por parte dos alunos durante a aula; tratar os conhecimentos científicos voltados para a realidade do aluno; fazer com que os alunos percebam tanto os benefícios da ciência e da tecnologia como as limitações de ambas para resolver os complexos problemas sociais; não se restringir a uma ação unicamente no âmbito da sala de aula; e educar para a vida e para viver. Por outro lado, Martins (2002) aponta alguns obstáculos à implementação de uma orientação CTS na escola, dispostos em três eixos: formação, concepções, crenças e atitudes dos professores; sequência rígida dos programas escolares; e os recursos didáticos. Embora esses obstáculos estejam mutuamente articulados, neste trabalho, buscamos focar a análise sobre a identificação de dificuldades que possam estar relacionadas com as concepções e ações dos professores em suas salas de aula. 
Analisando a implementação de uma abordagem ...

Considerando as discussões apresentadas, buscamos analisar como professores de química implementaram uma abordagem CTS em suas salas de aula, e identificar aspectos da prática docente que poderiam se constituir como obstáculos vivenciados por esses professores quando da implementação de uma proposta inovadora de ensino.

\section{Metodologia}

Este estudo é parte de uma pesquisa mais ampla desenvolvida em uma dissertação de mestrado que tratou da implementação de uma abordagem CTS no Ensino da Química e envolveu três professores de química de diferentes escolas públicas de Recife. Numa etapa anterior, esses professores foram entrevistados e participaram de encontros com a pesquisadora com o objetivo de discutir sobre as suas concepções de ciência, tecnologia, sociedade e inter-relações CTS (FIRME; AMARAL, 2008), e de planejar uma proposta de intervenção didática nessa perspectiva para ser aplicada em suas salas de aulas. Os professores elaboraram um planejamento único para ser aplicado, no qual foi escolhido trabalhar com a questão socioambiental do descarte das pilhas, explorando conceitos da eletroquímica. Neste trabalho, analisamos como dois professores de química (professora A e professor B) implementaram uma abordagem CTS em suas salas de aula e buscamos identificar aspectos da prática docente que poderiam se constituir como obstáculos para o êxito da sequência planejada. A análise foi de natureza qualitativa e, para a coleta de dados, optamos por uma observação não participante, ainda que tenha havido uma participação nossa nas etapas que antecederam a intervenção (entrevistas e encontros com os professores). Os registros da ação dos professores em sala de aula foram realizados por meio de caderno de campo e gravação em áudio e vídeo de uma intervenção didática da professora A e duas intervenções didáticas do professor B. Para a estruturação e apresentação dos dados, tomamos por base estratégias sugeridas por Amaral e Mortimer (2006) a partir de aspectos da etnografia interacional (CASTANHEIRA, 2004 apud AMARAL; MORTIMER, 2006) - que considera as especificidades de cada grupo social na constituição da linguagem e dos modos de ação utilizados pelos sujeitos, e propõe uma abordagem combinando discurso e etnografia para a investigação do processo de ensino-aprendizagem em sala de aula (AMARAL; MORTIMER, 2006). Nesse sentido, buscamos retratar o contexto da sala de aula pesquisada, nas quais as atividades foram desenvolvidas e situar o discurso produzido a partir de mapas representativos, usados para contextualizar os enunciados e orientar a escolha de episódios relevantes para a análise desses enunciados. Consideramos que tais enunciados estão inseridos numa cadeia de comunicação e não são indiferentes ou autossuficientes (BAKHTIN, 1992). Dessa forma, os episódios escolhidos para análise são parte de uma cadeia de eventos desenvolvidos na aula e possibilitam uma análise dos processos que ocorrem nesse contexto (AMARAL; MORTIMER, 2006). Os episódios selecionados e analisados foram transcritos, e as transcrições, organizadas em turnos.

Para a análise de aspectos relevantes da prática docente dos professores envolvidos na pesquisa, utilizamos a estrutura analítica da atividade discursiva nas salas de aula de ciências, proposta por Mortimer e Scott (2002). A estrutura analítica tem como objetivo caracterizar as formas como professores e alunos interagem no processo de construção de significados pelo uso da linguagem e toma por base a concepção de discurso proposta por Bakhtin (1992). Cinco 
aspectos são propostos para a análise: intenções do professor, conteúdo, abordagem comunicativa, padrões de interação e intervenção do professor. Com base nos objetivos propostos neste trabalho, a nossa análise contemplou os seguintes aspectos: intenções do professor, formas de abordagem comunicativa e formas de intervenção apresentadas pelos professores durante a intervenção didática. Com isso, analisamos as intenções ou objetivos dos professores na sala de aula quando eles buscavam articular os conceitos químicos aos contextos tecnológico e social. Quanto à abordagem comunicativa, considerada por Mortimer e Scott (2002) como aspecto central na estrutura analítica, analisamos as formas de comunicação instituídas no contexto das aulas sob duas dimensões - a dimensão dialógica/de autoridade e a dimensão interativa/não interativa - a partir das quais os autores propõem quatro tipos de abordagens comunicativas que caracterizam a comunicação entre professor e alunos: interativa/dialógica, interativa/de autoridade, não interativa/dialógica e não interativa/de autoridade. Cada uma dessas quatro classes está relacionada à forma como o professor conduz o discurso na aula. Nesse sentido, na abordagem interativa/dialógica, professores e alunos participam do processo comunicativo no qual diferentes pontos de vista são considerados. $\mathrm{Na}$ abordagem interativa/de autoridade, a comunicação envolve a participação do professor e alunos, porém contempla unicamente o ponto de vista científico. $\mathrm{Na}$ abordagem não interativa/dialógica, o professor está envolvido na ação comunicativa contemplando tanto os pontos de vista dos alunos como o ponto de vista científico. E, na abordagem não interativa/de autoridade, o professor é o único sujeito da ação comunicativa e aborda apenas o ponto de vista científico (MORTIMER; SCOTT, 2002). Quanto às intervenções do professor, analisamos formas de intervenção que contribuíram para fortalecer características propostas na abordagem CTS planejada. Consideramos, dentre outras, as formas apresentadas por Mortimer e Scott (2002): dando forma aos significados, selecionando significados, marcando significados-chave, compartilhando significados, checando o entendimento do aluno e revendo significados.

\section{O contexto das aulas de Química analisadas}

Para a investigação proposta, procuramos nos inserir no cotidiano dos professores envolvidos, na tentativa de construírmos uma melhor análise de aspectos de suas práticas docentes. Nesse sentido, a convivência com as turmas e a observação da prática docente dos professores ocorreu em momentos anteriores à aplicação da abordagem planejada. As aulas observadas foram registradas em vídeo e esses dados foram relevantes para constatarmos que, durante a implementação da abordagem CTS, os professores adotaram estratégias didáticas bastante diferentes daquelas vivenciadas no seu cotidiano escolar.

A intervenção didática com abordagem CTS, planejada anteriormente, foi realizada pela professora A com uma turma da $3^{a}$ série do Ensino Médio de uma escola pública, em horário extraescolar, para cumprir uma necessidade de reposição de aulas em uma das turmas. Dessa forma, a intervenção didática se deu num único momento, com duração de quatro horas e dez minutos de aula, correspondentes a cerca de cinco aulas de cinquenta minutos cada. Este único momento de aula foi referido como aula $\mathrm{A}$. As atividades vivenciadas na aula A foram realizadas no laboratório de química da escola, onde havia estrutura adequada para a realização das atividades, e dela participaram 11 alunos. 
Para o professor $\mathrm{B}$, a intervenção pedagógica foi realizada com uma turma da $2^{\mathrm{a}}$ série do Ensino Médio de uma escola pública, em horário escolar, e ocorreu em dois dias, contemplando quatro aulas de cinquenta minutos (duas aulas geminadas a cada dia), que foram denominadas aula $1 \mathrm{~B}$ e aula $2 \mathrm{~B}$. As atividades vivenciadas nas aulas $1 \mathrm{~B}$ e $2 \mathrm{~B}$ foram realizadas em outra sala de aula oferecida pela diretora pelo fato de ser climatizada e ter melhor acústica. Participaram das aulas 1B e 2B, em média, 22 alunos.

\section{Resultados e discussão}

A análise das aulas foi feita a partir de alguns procedimentos, como segue: elaboração de mapa de atividades da sequência das aulas com o objetivo de obtermos uma visão geral de como ocorreram essas aulas; seleção de episódios que representaram aspectos relevantes para uma orientação de ensino CTS; transcrição e análise dos respectivos episódios; e elaboração de quadros de síntese para a análise dos episódios e para a sequência das aulas, conforme descrito na metodologia. Para a análise de cada uma das intervenções aplicadas pelos professores A e B, foram extraídos três episódios, discriminados no Quadro 2.

Quadro 2. Episódios extraídos das intervenções aplicadas pelos professores Ae B.

\begin{tabular}{|l|l|}
\hline \multicolumn{1}{|c|}{ Aula A } & \multicolumn{1}{|c|}{ Aulas 1B e 2B } \\
\hline $\begin{array}{l}\text { Episódio 1A: Contextualizando os conceitos químicos } \\
\text { na sala de aula. Episódio 2A: Abordando os conceitos } \\
\text { químicos na sala de aula. Episódio 3A: Ampliando } \\
\text { reflexões sobre a problemática do descarte das pilhas } \\
\text { na sala de aula. }\end{array}$ & $\begin{array}{l}\text { Episódio 1B: Introduzindo a temática social na sala } \\
\text { de aula.Episódio 2B: Articulando os conceitos } \\
\text { químicos na sala de aula. Episódio 3B: Retomando a } \\
\text { temática social na sala de aula. }\end{array}$ \\
\hline
\end{tabular}

Para ilustrar a análise feita neste trabalho, apresentamos para cada professor: um recorte dos mapas de atividades elaborados para a aula A (professora A) e para as aulas 1B e 2B (professor B), tomando por base os episódios 3A e 3B; trechos transcritos e analisados dos respectivos episódios; e quadros de síntese da análise para toda a sequência das aulas (aula $\mathrm{A}$ e aulas 1B e 2B).

Inicialmente, apresentamos os dados e discussões relativos à professora $\mathrm{A}$ e, em seguida, os dados e discussões relativos ao professor B, e, posteriormente, uma análise conjunta para os dois professores.

Professora A: $\mathrm{Na}$ sua aula, a professora A desenvolveu atividades, como: leitura de textos, discussões no grande grupo, atividade experimental e aula expositiva. Os alunos participaram mais ativamente das leituras dos textos e da atividade experimental do que das discussões no grande grupo e da aula expositiva. A seguir, apresentamos um trecho do mapa de atividades elaborado para a aula $A$, conforme descrito no Quadro 3. 
Firme, R. N.; Amaral, E. M. R.

Quadro 3. Trecho do mapa de atividades da aula A.

\begin{tabular}{|c|l|l|l|l|}
\hline $\begin{array}{c}\text { Tempo } \\
\text { (duração) }\end{array}$ & \multicolumn{1}{|c|}{$\begin{array}{c}\text { Atividades } \\
\text { desenvolvidas }\end{array}$} & Principais temas & \multicolumn{1}{|c|}{$\begin{array}{c}\text { Ações dos } \\
\text { participantes }\end{array}$} & Comentários \\
\hline *198' $^{20}$ & $\begin{array}{l}\text { Atividade em grupo: } \\
\text { leitura de um texto e } \\
\text { respostas às questões } \\
\text { propostas pela } \\
\text { professora. } \\
\text { Discussões em } \\
\text { pequenos grupos. }\end{array}$ & $\begin{array}{l}\text { Introdução do tema } \\
\text { social: o aspecto } \\
\text { socioambiental do } \\
\text { descarte das pilhas. }\end{array}$ & $\begin{array}{l}\text { Os alunos, em seus } \\
\text { grupos, receberam um } \\
\text { texto e foram solicitados } \\
\text { a responderem } \\
\text { questões elaboradas } \\
\text { previamente pela } \\
\text { professora. }\end{array}$ & $\begin{array}{l}\text { Neste momento, os } \\
\text { alunos discutiam em } \\
\text { seus grupos e a } \\
\text { professora não } \\
\text { interferiu na } \\
\text { discussão. }\end{array}$ \\
\hline 25 ' & $\begin{array}{l}\text { Socialização das } \\
\text { respostas dos grupos } \\
\text { com o grande grupo. } \\
\text { Episódio 3A: } \\
\text { Ampliando reflexões } \\
\text { sobre a problemática } \\
\text { do descarte das } \\
\text { pilhas na sala de } \\
\text { aula. }\end{array}$ & $\begin{array}{l}\text { A problemática do } \\
\text { descarte das pilhas. } \\
\text { O tempo de vida } \\
\text { das pilhas. As } \\
\text { consequências } \\
\text { ambientais desse } \\
\text { descarte. A } \\
\text { contaminação com } \\
\text { metais pesados } \\
\text { presentes na pilha. }\end{array}$ & $\begin{array}{l}\text { Após a discussão nos } \\
\text { pequenos grupos, um } \\
\text { aluno de cada grupo } \\
\text { socializava as respostas } \\
\text { do seu grupo com a } \\
\text { turma. Entretanto, } \\
\text { outros alunos também } \\
\text { se colocavam. }\end{array}$ & $\begin{array}{l}\text { A professora se } \\
\text { apresentava satisfeita } \\
\text { com as respostas } \\
\text { os posicionamentos } \\
\text { dos alunos durante a } \\
\text { discussão. }\end{array}$ \\
\hline
\end{tabular}

" O tempo de 198' foi o total de minutos utilizados nas atividades anteriores.

Como podemos observar neste recorte do mapa de atividades, o Episódio 3A foi extraído do momento da aula em que professora e alunos socializavam com o grande grupo reflexões sobre um texto que tratava da problemática do descarte das pilhas no meio ambiente. Consideramos este momento relevante porque ele traduz os objetivos propostos pela orientação CTS, no sentido de discutir problemas sociais implicados nas aplicações científicas e tecnológicas. A professora buscou conduzir a discussão a partir de algumas questões propostas sobre o texto, mas outros aspectos relacionados ao tema emergiram naquele momento, como podemos constatar no trecho do Episódio 3A.

A partir da análise do Episódio 3A, verificamos que a professora parece ter possibilitado aos alunos a compreensão sobre a problemática do descarte das pilhas no meio ambiente de forma não adequada. Naquele momento, ela estava retomando a questão social após os estudos sobre pilhas. A retomada da questão social a partir da compreensão dos conceitos químicos tem papel central na perspectiva de ensino CTS. Entretanto, não identificamos, naquele momento da aula, uma articulação entre os conceitos químicos tratados anteriormente e a questão do descarte das pilhas, ou seja, uma aplicação dos conceitos químicos envolvidos no funcionamento das pilhas como um modelo explicativo para as causas e consequências de seu descarte em locais não apropriados. Quanto aos aspectos da prática docente, verificamos que a professora $\mathrm{A}$, ao longo de todo o episódio, teve como intenções: apresentar a temática social do descarte das pilhas (turnos 1-8); explorar a problemática (turnos 9-27); explicar o porquê do descarte das pilhas se constituir como um problema social (turnos 29-36); conscientizar os alunos sobre o problema (turnos 38-44); e desenvolver, nos alunos, atitudes mais responsáveis diante da problemática (turnos 44-58). Com relação à abordagem comunicativa, a professora 
Analisando a implementação de uma abordagem ...

\section{Episódio 3A: Ampliando reflexões sobre a problemática do descarte das pilhas na sala de aula.}

30 - A (fazendo a leitura das respostas do grupo): "Por que as pilhas e baterias não devem ir para os aterros?"

31 - P: "Então, por que as pilhas e baterias, quando você joga no lixo doméstico, qual o caminho delas?"

32 - A: "Aterro".

33 - P: "Vão para os aterros sanitários. Então aí, ele (o texto) está dizendo por que as pilhas não devem ir para os aterros sanitários. Vamos lá?"

34 - A (fazendo a leitura das respostas do grupo): "Em função do que foi apresentado, concluímos que as pilhas e baterias quando esgotadas, seu potencial energético tornam-se resíduos perigosos e como tal, deveriam ser encaminhadas para a reciclagem ou para o aterro industrial".

... (Durante este intervalo, a professora e alunos discutem aspectos que vão desde o descarte das pilhas nos aterros ou lixões até a contaminação de lençóis freáticos, e, por conseguinte, contaminação da cadeia alimentar pela ingestão, por exemplo, de produtos agrícolas irrigados pela água contaminada.)

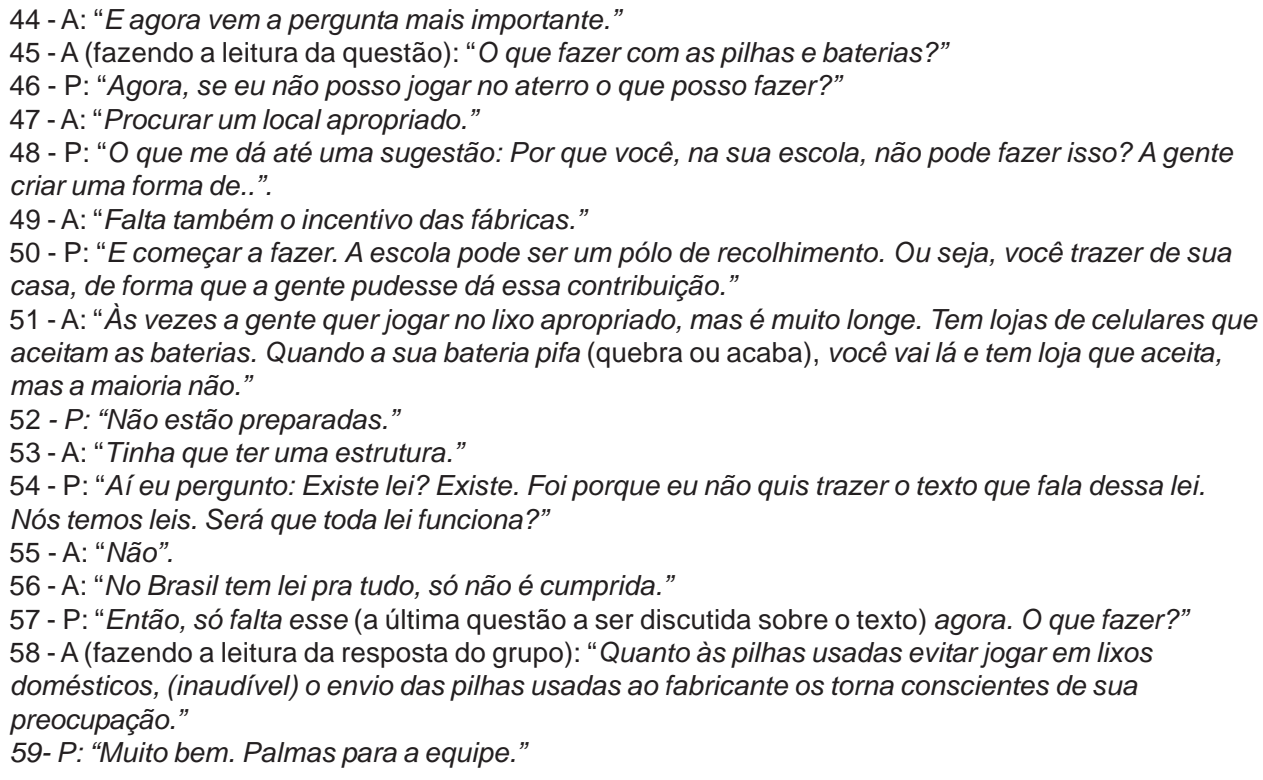

desenvolveu um discurso caracterizado como interativo/dialógico, uma vez que foram considerados, pela professora e alunos, pontos de vistas relacionados a contextos diversos. Sobre as formas de intervenção, a professora: explorou as ideias dos alunos (turno 1); deu forma aos significados quando articulou informações do texto com causas e consequências do descarte das pilhas (turnos 5-47); e compartilhou significados quando socializou as respostas propostas pelos grupos (5-59).

Esta análise foi feita para os três episódios da aula A. O procedimento de transcrição e análise dos episódios possibilitou a elaboração de um quadro de síntese dos resultados dessas análises (Quadro 4) com o objetivo de ampliarmos a nossa compreensão de como a professora A implementou uma abordagem CTS em sua sala de aula e identificarmos alguns obstáculos que emergiram desse processo. 
Firme, R. N.; Amaral, E. M. R.

Quadro 4. Síntese da análise da aula A

\begin{tabular}{|c|c|c|c|}
\hline $\begin{array}{c}\text { Episódios } \\
\text { Turnos e sujeitos }\end{array}$ & $\begin{array}{l}\text { Intenções } \\
\text { do professor }\end{array}$ & $\begin{array}{l}\text { Abordagem } \\
\text { comunicativa }\end{array}$ & $\begin{array}{c}\text { Formas } \\
\text { de intervenção }\end{array}$ \\
\hline \multicolumn{4}{|c|}{ Episódio 1A: Contextualizando os conceitos químicos na sala de aula } \\
\hline $\begin{array}{l}\text { Turnos } 7-15 \\
\text { (professora e alunos) } \\
\text { Turnos } 20-37 \\
\text { (professora e alunos) } \\
\text { Turnos } 38-45 \\
\text { (professora e alunos) }\end{array}$ & $\begin{array}{l}\text { Articular conceitos } \\
\text { científicos com o } \\
\text { cotidiano. } \\
\text { Explorar a compreensão } \\
\text { dos alunos. } \\
\text { Introduzir a terminologia } \\
\text { científica. }\end{array}$ & Interativa/dialógica & $\begin{array}{l}\text { Dando forma aos } \\
\text { significados dos } \\
\text { conceitos químicos. }\end{array}$ \\
\hline \multicolumn{4}{|c|}{ Episódio 2A: Abordando os conceitos químicos na sala de aula } \\
\hline $\begin{array}{l}\text { Turnos 1-6 } \\
\text { (professora e alunos) } \\
\text { Turnos } 7-39 \\
\text { (professora e alunos) } \\
\text { Turnos 40-50 } \\
\text { (professora e alunos) } \\
\text { Turnos 55-57 } \\
\text { (professora e alunos) } \\
\text { Turnos 58-81 } \\
\text { (professora e alunos) }\end{array}$ & $\begin{array}{l}\text { Recuperar as ideias dos } \\
\text { alunos. } \\
\text { Explorar os resultados } \\
\text { obtidos na atividade } \\
\text { experimental. } \\
\text { Aplicar os conceitos em } \\
\text { situações práticas } \\
\text { associadas ao contexto } \\
\text { tecnológico. } \\
\text { Introduzir os conceitos de } \\
\text { pilhas na sala de aula. } \\
\text { Discutir conceitos } \\
\text { químicos que podem } \\
\text { explicar o funcionamento } \\
\text { da pilha. }\end{array}$ & Interativa/De autoridade & $\begin{array}{l}\text { Revendo os resultados } \\
\text { da atividade experimental } \\
\text { com o objetivo de marcar } \\
\text { significados-chave. } \\
\text { Compartilhando } \\
\text { significados-chave e } \\
\text { checando o entendimento } \\
\text { dos alunos. } \\
\text { Dando forma aos } \\
\text { significados. } \\
\text { Desenvolvendo as ideias } \\
\text { científicas a respeito das } \\
\text { pilhas. }\end{array}$ \\
\hline \multicolumn{4}{|c|}{ Episódio 3A: Ampliando reflexões sobre a problemática do descarte das pilhas na sala de aula } \\
\hline $\begin{array}{l}\text { Turnos 1-8 } \\
\text { (professora e alunos) } \\
\text { Turnos 9-27 } \\
\text { (professora e alunos) } \\
\text { Turnos 29-36 } \\
\text { (professora e alunos) }\end{array}$ & $\begin{array}{l}\text { Apresentar a temática } \\
\text { social. } \\
\text { Explorar a problemática. } \\
\text { Explicar o porquê do } \\
\text { descarte das pilhas e } \\
\text { baterias se constituir como } \\
\text { uma problemática social. } \\
\text { Conscientizar os alunos. } \\
\text { Desenvolver nos alunos } \\
\text { atitudes mais } \\
\text { responsáveis. }\end{array}$ & $\begin{array}{l}\text { Interativa/ } \\
\text { dialógica }\end{array}$ & $\begin{array}{l}\text { Dando forma aos } \\
\text { significados frente à } \\
\text { problemática em estudo. } \\
\text { Compartilhando } \\
\text { significados com o } \\
\text { grande grupo. }\end{array}$ \\
\hline
\end{tabular}


Um aspecto importante a ser mencionado diz respeito a uma dinâmica de aula que não fazia parte do planejamento proposto nos encontros com os professores. Dessa forma, constamos que, numa perspectiva de ensino CTS, alguns aspectos da prática docente da professora A sofreram modificações ainda que pontuais ou circunstanciais. De um modo geral, observamos que a professora A, na implementação de uma abordagem CTS em sua sala de aula, ressaltou com mais ênfase a influência da ciência e da tecnologia na sociedade do que o inverso. Em alguns momentos, verificamos que ela buscou conscientizar os alunos sobre a possibilidade de participação da sociedade na solução de problemas socioambientais relativos ao desenvolvimento científico e tecnológico. No entanto, no desenvolvimento das atividades em sala de aula, o tema social não foi o fator determinante para a discussão dos conteúdos científicos por ela abordados, diferentemente do que alguns autores sugerem para essa perspectiva de ensino. Não obstante, a professora conseguiu articular a relação mútua da ciência, tecnologia e sociedade em sua sala de aula, embora não tenha dado igual ênfase a cada uma dessas dimensões. Tal postura parece refletir algumas concepções apresentadas pela professora (FIRME; AMARAL, 2008), por exemplo, quando atribui uma maior valorização dos aspectos científicos com relação aos aspectos tecnológicos e sociais. Quanto aos aspectos da prática docente, a professora A contextualizou os conceitos científicos, diversificou as estratégias metodológicas, possibilitou discursos interativo/dialógico e interativo/de autoridade nos momentos pertinentes, e promoveu diferentes formas de intervenção (ver Quadro 4). Em resumo, na forma como a professora A buscou fazer uma abordagem CTS, percebemos que os aspectos tecnológico e social foram pouco explorados em sala de aula.

Professor B: $\mathrm{Na}$ sua aula, o professor B desenvolveu atividades como: leitura de texto, discussão no grande grupo sobre o texto, aula expositiva e atividade em grupo. Os alunos participaram mais ativamente da leitura do texto, da discussão no grande grupo e da atividade em grupo - elaboração de cartazes com soluções alternativas para a problemática do descarte das pilhas e baterias - do que da abordagem dos conceitos científicos. A seguir, apresentamos um trecho do mapa de atividades elaborado para a aula $2 \mathrm{~B}$, conforme descrito no Quadro 5.

Neste recorte do mapa de atividades, o Episódio 3B foi extraído do momento da aula em que o professor levantou alguns aspectos tratados na aula anterior (aula 1B), como, por exemplo, os metais pesados e os prejuízos causados por eles ao meio ambiente, e reforçou a questão social solicitando, aos alunos, que apresentassem posicionamentos e alternativas frente à problemática do descarte das pilhas. Mais uma vez, consideramos este momento da aula relevante numa perspectiva de ensino CTS.

$\mathrm{Na}$ análise do episódio 3B, verificamos que o professor procurou ressaltar as interrelações CTS quando mencionou a problemática social, associou essa problemática ao aparato tecnológico pilhas e colocou os conceitos químicos como meio de compreensão do funcionamento das pilhas. Quanto aos aspectos da prática docente, o professor B, ao longo do episódio, teve como intenções: articular conceitos químicos com os aparatos tecnológicos e com a problemática do descarte das pilhas (turno 1); resgatar ideias acerca do problema do descarte das pilhas (turnos 1-4); e desenvolver reflexões e atitudes críticas frente à problemática abordada (turnos 5-8). Quanto à abordagem comunicativa, o discurso se caracterizou como intera- 
Firme, R. N.; Amaral, E. M. R.

tivo/de autoridade pelo fato de o professor, de certa forma, direcionar o posicionamento dos alunos diante do problema (turnos 1-4). Entretanto, quando deixou os alunos à vontade para expressarem suas sugestões para minimizar consequências do descarte das pilhas, o discurso caracterizou-se como interativo/dialógico. Sobre as formas de intervenção, o professor B: marcou significados-chave para o descarte das pilhas como uma problemática social e compartilhou significados quando socializou as sugestões dos grupos para o grande grupo.

Quadro 5. Trecho do mapa de atividades da aula 2B.

\begin{tabular}{|c|c|c|c|c|}
\hline $\begin{array}{c}\text { Tempo } \\
\text { (duração) }\end{array}$ & $\begin{array}{c}\text { Atividades } \\
\text { desenvolvidas }\end{array}$ & $\begin{array}{l}\text { Principais } \\
\text { temas }\end{array}$ & Ações dos participantes & Comentários \\
\hline \multicolumn{5}{|l|}{ * 35} \\
\hline 28 & $\begin{array}{l}\text { Retorno à temática } \\
\text { social. } \\
\text { Episódio 3B: } \\
\text { Retomando a } \\
\text { temática social na } \\
\text { sala de aula. } \\
\text { Elaboração de } \\
\text { cartazes pelos } \\
\text { alunos. }\end{array}$ & $\begin{array}{l}\text { Soluções } \\
\text { alternativas para } \\
\text { a problemática } \\
\text { do descarte das } \\
\text { pilhas. }\end{array}$ & $\begin{array}{l}\text { O professor faz alguns } \\
\text { comentários sobre a presença } \\
\text { dos metais pesados no meio } \\
\text { ambiente e os prejuízos por eles } \\
\text { causados. } \\
\text { O professor solicita aos alunos } \\
\text { que se dividam em grupos e } \\
\text { elaborem cartazes para } \\
\text { expressarem suas ideias e/ou } \\
\text { sugestões quanto à problemática } \\
\text { do descarte das pilhas. }\end{array}$ & $\begin{array}{l}\text { Neste momento, os } \\
\text { alunos escutam o } \\
\text { professor em } \\
\text { silêncio. } \\
\text { Os alunos } \\
\text { participaram } \\
\text { ativamente da } \\
\text { atividade em grupo. }\end{array}$ \\
\hline $15^{\prime}$ & $\begin{array}{l}\text { Apresentação dos } \\
\text { cartazes elaborados } \\
\text { para o grande grupo. }\end{array}$ & $\begin{array}{l}\text { Soluções } \\
\text { alternativas para } \\
\text { a problemática } \\
\text { do descarte das } \\
\text { pilhas. }\end{array}$ & $\begin{array}{l}\text { Os grupos socializaram com o } \\
\text { grande grupo suas sugestões } \\
\text { para minimizar o problema } \\
\text { ambiental causado pelo descarte } \\
\text { das pilhas em locais não } \\
\text { apropriados. }\end{array}$ & $\begin{array}{l}\text { Dois alunos de cada } \\
\text { grupo } \\
\text { apresentaram, para } \\
\text { o grande grupo, os } \\
\text { cartazes por eles } \\
\text { elaborados. }\end{array}$ \\
\hline
\end{tabular}

* O tempo de 35' foi o total de minutos utilizados nas atividades anteriores.

Episódio 3B: Retomando a questão social na sala de aula.

1 - P: "Baseado nestes conceitos, a semana passada a gente falou no aspecto social de trabalhar com metais. Alguns desses metais são chamados de metais pesados, e que podem trazer o quê? Prejuízos [...]. E percebemos que algumas tecnologias, como, por exemplo, as pilhas e baterias de celular que nós usamos bastante, mas sem os fundamentos teóricos, a informação científica. O que a gente trabalhou agora? Conceito de pilhas. Baseado neste contexto, o que eu vou pedir a vocês? Vou pedir que vocês façam um elo de ligação entre o que a gente conversou na aula passada o que a gente viu em termos de conceitos até agora. Não só o conceito de pilhas, mas também a importância desse conceito em seu uso. Pessoal, hoje se perguntarem a vocês: eu posso pegar qualquer pilha dessas alcalinas e jogar fora em qualquer lugar?"

2 - A: "Não".

3 - P: "Você sabe que se fizer isso pode trazer prejuízos ao meio ambiente. Concordam comigo?"

4 - A: "Sim".

5 - P: "Então o que vamos fazer? [...] Vocês vão citar de forma resumida, através de desenhos ou frases, de que forma, a partir do que a gente acabou de ver, [...]"

(O professor explica aos alunos como devem proceder na atividade e solicita que se organizem em pequenos grupos.)

6 - P: "Vocês vão tentar elaborar um cartaz sugerindo soluções em relação à problemática social. De que forma nós poderíamos resolver isto?" 
Analisando a implementação de uma abordagem ...

Como feito com a análise da professora $\mathrm{A}$, analisamos os três episódios extraídos das aulas $1 \mathrm{~B}$ e $2 \mathrm{~B}$ do professor $\mathrm{B}$. O procedimento de transcrição e análise dos episódios possibilitou a elaboração de um quadro de síntese dos resultados dessas análises (Quadro 6) com o objetivo de ampliarmos a nossa compreensão de como o professor B implementou uma abordagem CTS em sua sala de aula e identificarmos alguns obstáculos que emergiram desse processo.

Quadro 6. Síntese da análise das aulas 1B e 2B.

\begin{tabular}{|c|c|c|c|}
\hline $\begin{array}{c}\text { Episódios } \\
\text { Turnos e sujeitos }\end{array}$ & $\begin{array}{l}\text { Intenções } \\
\text { do professor }\end{array}$ & $\begin{array}{l}\text { Abordagem } \\
\text { comunicativa }\end{array}$ & $\begin{array}{c}\text { Formas } \\
\text { de intervenção }\end{array}$ \\
\hline \multicolumn{4}{|c|}{ Episódio 1B: Introduzindo a temática social na sala de aula } \\
\hline $\begin{array}{l}\text { Turno } 4 \text { (professor) } \\
\text { Turnos 15-38 } \\
\text { (professor e alunos) } \\
\text { Turnos 15-41 } \\
\text { (professor e alunos) } \\
\text { Turno 34 } \\
\text { (professor) }\end{array}$ & $\begin{array}{l}\text { Situar o tema na sala de } \\
\text { aula: a problemática do } \\
\text { descarte das pilhas e } \\
\text { baterias. } \\
\text { Explorar as informações } \\
\text { trazidas no texto. } \\
\text { Explicar os conceitos } \\
\text { químicos presentes no } \\
\text { texto. } \\
\text { Inserir os metais pesados } \\
\text { na problemática do } \\
\text { descarte das pilhas e } \\
\text { baterias. }\end{array}$ & Interativa/de autoridade & $\begin{array}{l}\text { Dando forma aos } \\
\text { significados. } \\
\text { Selecionando e } \\
\text { marcando significados. } \\
\text { Revendo significados. }\end{array}$ \\
\hline \multicolumn{4}{|c|}{ Episódio 2B: Articulando os conceitos químicos em sala de aula } \\
\hline $\begin{array}{l}\begin{array}{l}\text { Turnos 1-10 } \\
\text { (professor) }\end{array} \\
\text { Turnos 11-13 } \\
\text { (professor e alunos) }\end{array}$ & $\begin{array}{l}\text { Retomar as questões do } \\
\text { descarte das pilhas e } \\
\text { baterias. } \\
\text { Caracterizar pilhas e } \\
\text { baterias como tecnologias } \\
\text { desenvolvidas a partir dos } \\
\text { conceitos químicos. } \\
\text { Explicar os conceitos } \\
\text { químicos envolvidos no } \\
\text { funcionamento das pilhas. }\end{array}$ & $\begin{array}{l}\text { Não interatival } \\
\text { de autoridade }\end{array}$ & $\begin{array}{l}\text { Revendo significados. } \\
\text { Dando forma aos } \\
\text { significados. } \\
\text { Selecionando, marcando } \\
\text { e checando significados- } \\
\text { chave. }\end{array}$ \\
\hline \multicolumn{4}{|c|}{ Episódio 3B: Retomando a temática social na sala de aula } \\
\hline $\begin{array}{l}\text { Turnos 1-4 } \\
\text { (professor e alunos) } \\
\text { Turnos 5-8 } \\
\text { (Professor e alunos) }\end{array}$ & $\begin{array}{l}\text { Articular os conceitos com } \\
\text { os aparatos tecnológicos e } \\
\text { com a problemática do } \\
\text { descarte das pilhas. } \\
\text { Resgatar ideias acerca do } \\
\text { problema do descarte das } \\
\text { pilhas. } \\
\text { Desenvolver reflexões e } \\
\text { atitudes críticas frente à } \\
\text { problemática abordada. }\end{array}$ & Interativa/de autoridade & $\begin{array}{l}\text { Compartilhando } \\
\text { significados }\end{array}$ \\
\hline
\end{tabular}


De um modo geral, observamos que o professor B, na implementação de uma abordagem CTS em sua sala de aula, procurou ser mais fiel ao planejamento feito anteriormente. Com isso, desenvolveu um discurso mais próximo das propostas discutidas nos encontros docentes. Para o professor B, o tema social foi determinante no desenvolvimento das atividades e discussões e isso evidencia que ele assumiu a proposta de implantar uma abordagem CTS, na qual o tema social orientava a discussão na sala de aula. É interessante ressaltar que os momentos vivenciados parecem ser representativos de uma ruptura, não necessariamente definitiva, com as estratégias didáticas usuais do professor naquela turma, considerando que, em momentos anteriores à aplicação da abordagem planejada, predominaram, em sua sala de aula, atividades como exposição de conteúdos e resolução de exercícios. Quanto aos aspectos da prática docente, o professor $\mathrm{B}$ diversificou as intenções imprimindo uma boa dinâmica na sala de aula. A interação do professor com os alunos caracterizou-se, predominantemente, como interativa/de autoridade, uma vez que a participação dos alunos se limitou à complementação de frases e respostas curtas, e, na tentativa de articular as inter-relações CTS, o professor fazia prevalecer o ponto de vista científico nas discussões. Quanto às formas de intervenção, o professor pareceu selecionar e marcar significados unicamente na perspectiva científica (ver quadro 6). Assim, entendemos que a forma como o professor B conduziu a interação com a turma e a tendência do mesmo em selecionar e marcar significados do ponto de vista apenas científico pareceram prejudicar alguns dos objetivos propostos pela perspectiva de ensino CTS. Isso constituiu um obstáculo para a implementação de uma abordagem CTS na sala de aula do referido professor.

\section{Síntese da análise para os dois professores}

Um ponto a ser considerado na análise das intervenções da professora A e do professor $\mathrm{B}$ é relativo à disponibilidade e uso do material didático. Primeiramente, é importante marcar que as discussões sobre temas sociais foram feitas, basicamente, a partir de textos paradidáticos. Isso pode ser considerado como evidência de uma formação inicial que não prepara adequadamente os professores para esse tipo de discussão. Além disso, representa uma constatação de que os recursos didáticos tradicionais da escola, marcadamente o livro didático, ainda não estão adequados à inovação do ensino. No entanto, mais uma vez identificamos diferentes formas de ação dos professores com relação a essa limitação de recursos. A professora $\mathrm{A}$ incluiu, nas atividades da sala de aula, a discussão de textos diversos e esclarecedores sobre o problema do descarte das pilhas, enquanto o professor B realizou a discussão do tema social basicamente a partir de um único texto, e apresentou uma interatividade limitada com os alunos, como já foi mencionado anteriormente.

Ainda com relação ao material didático, vale salientar que há dificuldade para se obterem informações detalhadas sobre aspectos científicos associados ao funcionamento e uso de artefatos tecnológicos. $\mathrm{Na}$ sala de aula, isso pode implicar uma abordagem superficial dos aspectos tecnológicos e uma compreensão limitada sobre os impactos da tecnologia na sociedade e no ambiente. Por exemplo, não é fácil encontrar informações técnicas e científicas sobre as diversas pilhas usadas no cotidiano e sobre as reais consequências do seu descarte aleatório em diferentes ambientes. Podemos somar a isso, a complexidade que o tema encerra 
Analisando a implementação de uma abordagem ...

e o desafio que é posto no sentido de tornar essas informações didaticamente viáveis para o trabalho em sala de aula.

A partir dos resultados mostrados neste trabalho, apontamos alguns prováveis obstáculos à implementação de uma abordagem CTS para o ensino e que podem ser divididos em dois tipos: aqueles relativos aos aspectos da prática docente e aqueles inerentes ao desafio proposto por este tipo de abordagem, sobretudo em relação à forma como o conhecimento pode ser tratado. Com relação ao primeiro tipo, podemos citar os seguintes obstáculos: as concepções dos professores parecem estar mais voltadas para o ensino de conceitos científicos, determinando um menor estatuto para as discussões dos aspectos sociais em sala de aula; podem ser encontrados diferentes níveis de disponibilidade dos professores às mudanças que emergem de propostas de ensino inovadoras; em geral, os professores adotam uma interatividade pouco significativa com os alunos, limitando o aparecimento de diferentes visões sobre o tema na discussão em sala de aula; a formação inicial não oferece possibilidades para professores que pretendam trabalhar com perspectivas de ensino inovadoras, uma vez que, geralmente, elas não são abordadas nos cursos universitários.

Para o segundo tipo de obstáculo, ressaltamos: a ausência de informações técnicas e científicas para melhor compreensão dos aparatos tecnológicos, o que pode contribuir para a limitada discussão do aspecto tecnológico em sala de aula; a velocidade com a qual a tecnologia se inova e que os professores não conseguem acompanhar nas suas aulas; a complexidade científica que, muitas vezes, está implicada no estudo de fenômenos/situações relevantes; a dificuldade de articularem, didaticamente, os conceitos científicos ensinados na escola com determinadas tecnologias associadas a um tema de alto valor social; a dificuldade de dispor de material didático que suporte as discussões na sala de aula.

\section{Considerações finais}

Com este estudo, analisamos como dois professores de química implementaram uma abordagem CTS em suas salas de aula. De uma forma geral, os professores tiveram mais facilidade de expressar suas ideias sobre os conceitos científicos do que sobre as questões da tecnologia e as questões sociais. É importante ressaltar que o planejamento conduziu, de forma muito marcante, as atividades da intervenção e as ações dos professores em sala de aula. A despeito do que foi colocado no planejamento, podemos perceber que cada professor traz, para as situações de ensino, elementos da sua própria forma de ser professor. Mesmo com um planejamento único verificamos diferenças nas formas de conduzir as atividades e discussões em sala de aula.

Ressaltamos que a perspectiva de ensino utilizada por esses professores foi consequência de um processo de formação iniciado fora da sala de aula e que foi continuado na experiência vivenciada nas aulas de quimica. Em outras palavras, após a discussão sobre a perspectiva CTS (etapa anterior apresentada em outro artigo), foi dada, aos professores, a oportunidade de fazerem uma tentativa de pôr em prática o que foi discutido. Constatamos esforços feitos pelos professores no sentido de cumprir uma meta anteriormente estabelecida, como uma tentativa de obter sucesso na implementação dessa nova proposta de ensino. No entanto, verificamos que, neste intento, as ações são fortemente guiadas pelas concepções que 
Firme, R. N.; Amaral, E. M. R.

os professores apresentam sobre CTS. Considerando os obstáculos apontados na discussão, possíveis caminhos podem ser buscados na tentativa de se alcançar mais êxito em uma abordagem CTS para o Ensino de Ciências. Algumas possibilidades seriam: incluir o tratamento de questões referentes à ciência, tecnologia e sociedade nos processos de formação inicial dos professores (a partir de disciplina específica, ou inseri-lo em disciplinas que abordam as metodologias de ensino e didática); incentivar os professores para a construção de uma postura reflexiva sobre a sua prática e sobre a atualização dos conteúdos disciplinares que estão ensinando; promover a formação continuada do professor acerca de conhecimentos científicos e tecnológicos relacionados a problemas sociais relevantes; incentivar a elaboração do material didático pelo professor; e buscar realizar um planejamento prévio para as intervenções didáticas, incluindo objetivos, estratégias de ensino, conceitos científicos e tecnológicos, e tema social definido.

Nesse sentido, entendemos que o interesse e a determinação em superar os desafios que emergem nos processos de inovação no ensino têm estreita relação com a disponibilidade e com o compromisso subjacente aos professores.

\section{Referências}

ACEVEDO DÍAZ, J. A. Cambiando la práctica docente en la enseñanza de las ciencias a través de CTS. Borrador, n.13, p. 26-30, 1996a. Disponível em: <http:// www.campusoei.org/salactsi/acevedo2.htm>. Acesso em: 26 maio 2006.

. La formación del profesorado de enseñanza secundaria y la educación CTS: una cuestión problemática. Revista Interuniversitaria de Formación del Profesorado, Zaragoza, v. 26, p. 131-144, 1996b. Disponível em: <http://www.campus-oei.org/salactsi/ acevedo9.htm>. Acesso em: 26 maio 2006.

ACEVEDO ROMERO, P.; ACEVEDO DÍAZ, J. A. Proyectos y materiales curriculares para la educación CTS: enfoques, estructuras, contenidos y ejemplos. Bordón, Madri, v. 54, n. 1, p. 5-18, 2002. Disponível em: <http://www.oei.es/salactsi/acevedo19.htm>. Acesso em: 26 maio 2006.

AMARAL, E. M. R.; MORTIMER, E. F. Uma metodologia para análise da dinâmica discursiva entre zonas de um perfil conceitual no discurso da sala de aula. In: SANTOS, F. M. T.; GREGA, U. I. M. (Orgs.). A pesquisa em ensino de ciências no Brasil e suas metodologias. Ijuí: Editora Unijuí, 2006. p. 239-296. (Coleção Educação em Ciências).

BAKHTIN, M. Marxismo e filosofia da linguagem. São Paulo: Hucitec, 1992.

BRASIL. Ministério da Educação. Secretaria de Educação Média e Tecnológica. Parâmetros Curriculares Nacionais: Ensino Médio. Brasília: Ministério da Educação, 2002.

BUSTAMANTE, J. A integração da ciência, tecnologia e sociedade: o grande desafio da educação no século XXI. Educação Brasileira, Brasília, v. 19, n. 39, p. 11-20, 1997. 
Analisando a implementação de uma abordagem ...

CACHAPUZ, A. et al. A necessária renovação do ensino de ciências. São Paulo: Cortez, 2005.

FIRME, R. N.; AMARAL, E. M. R. Concepções de professores de química sobre ciência, tecnologia, sociedade e suas inter-relações: um estudo preliminar para o desenvolvimento de abordagens CTS em sala de aula. Ciência \& Educação, Bauru, v. 14, n. 2, p. 251-269, 2008 .

MACEDO, B.; KATZKOWICK, R. Educação científica: sim, mas qual e como? In: MACEDO, B. (Org.). Cultura científica: um direto de todos. Brasília: Unesco; MEC, 2003. p. 65-84.

MARTINS, I. P. Problemas e perspectivas sobre a integração CTS no sistema educativo português. Revista Electrónica de Enseñanza de las Ciencias, Barcelona, v. 1, n. 1, p. 28-39, 2002. Disponível em < http://reec.uvigo.es/volumenes/volumen1/Numero1/ Art2.pdf>. Acesso em: 26 maio 2006.

Formação inicial de professores de física e química sobre a tecnologia e suas relações sócio-científicas. Revista Electrónica de Enseñanza de las Ciencias, Barcelona, v. 2, n. 3, p. 293-308, 2003. Disponível em: < http://reec.uvigo.es/volumenes/volumen2/ Numero3/Art6.pdf>. Acesso em: 26 maio 2006.

MORTIMER, E. F.; SCOT'T, P. H. Atividade discursiva nas salas de aula de ciências: uma ferramenta sociocultural para analisar e planejar o ensino. Investigações em Ensino de Ciências, Porto Alegre, v. 7, n. 3, p. 283-306, 2002. Disponível em: <http:// www.if.ufrgs.br/ienci/artigos/Artigo_ID94/v7_n3_a2002.pdf>. Acesso em: 15 set. 2006.

SANTOS, W. L.; SCHNETZLER, R. P. Função social: o que significa ensino de química para formar o cidadão? Química Nova na Escola, São Paulo, n. 4, p. 28-34, 1996.

Educação química: compromisso com a cidadania. Ijuí: Editora Unijuí, 1997.

TEIXEIRA, P. M. M. A educação científica sob a perspectiva da pedagogia histórico-social e do movimento CTS no ensino de ciências. Ciência \& Educação, Bauru, v. 9, n. 2, p. 177-190, 2003. 